\title{
Development of a laboratorial platform for diagnosis of schistosomiasis mansoni by PCR-ELISA
}

\author{
Carolina Senra ${ }^{1}$, Luciana Inácia Gomes ${ }^{1}$, Liliane Maria Vidal Siqueira², Paulo Marcos Zech Coelho², Ana Rabello \\ and Edward Oliveira ${ }^{1 *}$ (B)
}

\begin{abstract}
Objective: We developed a laboratorial platform to release a commercial platform used in the PCR-ELISA for the molecular diagnosis of schistosomiasis mansoni. On following, PCR-ELISA platform laboratorial was evaluated in 206 feces samples collected of individual living in a Brazilian low endemicity area.

Results: The PCR-ELISA laboratorial platform indicated a prevalence rate of $25.2 \%$, which was higher than the KatoKatz technique (18.4\%) and lower than the commercial platform (30.1\%). Considering Kato-Katz technique as the reference, there were $97.4 \%$ and $91.1 \%$ of relative sensitivity and specificity rates, respectively. The laboratorial platform presented good precision, performance diagnostic, and can be used in replacement to the commercial platform for diagnosis of schistosomiasis by PCR-ELISA.
\end{abstract}

Keywords: Schistosomiasis, Schistosoma mansoni, Diagnosis, PCR-ELISA, Disease control

\section{Introduction}

In Brazil, schistosomiasis is caused only by Schistosoma mansoni where was estimated $1 \%$ positive rate of schistosomiasis mansoni [1]. The laboratorial diagnosis is performed by the detection of $S$. mansoni using Kato-Katz technique [2] due to its practicability, efficacy, and low cost [3]. However, its sensitivity considerably decreases when used to diagnose cases post-treatment with praziquantel or in areas of low prevalence, where most individuals have low parasitic load $[4,5]$.

In this context, Pontes et al. [6] proposed a diagnostic by polymerase chain reaction (PCR) targeting a 110 base pair (bp) fragment from a $121 \mathrm{bp}$ tandem repeat deoxyribonucleic acid (DNA) sequence from the S. mansoni genome [7]. Then, Gomes et al. [8] standardized a polymerase chain reaction-enzyme-linked immunoassay (PCR-ELISA) to detect the same DNA sequence

\footnotetext{
*Correspondence: edwardjo@minas.fiocruz.br

${ }^{1}$ Clinical Research and Public Politics in Infectious and Parasitic Diseases, Instituto René Rachou, Oswaldo Cruz Foundation (IRR/FIOCRUZ), Av. Augusto de Lima, 1715, Belo Horizonte, MG 30190-002, Brazil Full list of author information is available at the end of the article
}

using a commercial platform (PCR Plate Detection Kit; Sigma-Aldrich, St. Louis, MI, US). Besides being capable of processing a large number of samples, this assay had sensitivity of $97.4 \%$, specificity of $85.1 \%$, and provided an analytical sensitivity of $1.3 \mathrm{fg}$ of DNA of S. mansoni, which is equivalent to 0.15 eggs/g of feces. However, the PCR Plate Detection Kit was discontinued by the manufacturer. In this study, we aimed to establish such test by developing a PCR-ELISA laboratorial platform for the molecular diagnosis of schistosomiasis mansoni.

\section{Main text \\ Methods}

This work was performed in two phases: (i) In a proof of concept phase, we standardized the PCR-ELISA laboratorial platform using genomic DNA of adult S. mansoni obtained from livers of Swiss albino mice 60 days after infection with 150 cercariae. The animals and cercariae were provided by the IRR/FIOCRUZ. (ii) In a phase II evaluation, the assay was validated in total DNA extracted stool samples from individuals living in the community of Pedra Preta, a rural locality of Montes 
Claros municipality considered a low endemicity area for schistosomiasis mansoni in the North of the state of Minas Gerais, Brazil. The population was constituted of 69 children (female/male: 33/36; age range of 1-17 years) and 137 adults (female/male: 66/71; age range of 18-86 years). We describe the step-by-step development of the PCR-ELISA platform laboratorial below.

\section{Proof of concept phase}

Genomic DNA was extracted from adult S. mansoni using QlAamp DNA Mini and Blood Mini Handbook (QIAGEN, GmbH, Hilden, GE), according to the manufacturer's protocol. The DNA concentration and purity were measured at 260 and $260 / 280 \mathrm{~nm}$ in a spectrophotometer Nanodrop ND-1000 (Thermo Fisher Scientific, Wilmington, DE, US). A highly repetitive genome sequence of parasites from the genus Schistosoma [7], (Gen Bank M61098) was amplified by PCR following the protocol described by Gomes et al. [8]. In each PCR assay, we included a negative control (PCR mix without DNA), and genomic DNA extracted from adult worms diluted 1:5 in linear acrylamide diluted in water $(1: 166 \mathrm{v} / \mathrm{v})$ was used as a positive control.

The best PCR-ELISA laboratorial platform protocol was defined. The wells of the MaxiSorp ${ }^{\circledR}$ polystyrene microplates (Nunc ThermoScientific, Vernon Hills, IL, US) were coated with $100 \mu \mathrm{l}$ of streptavidin (SigmaAldrich, Co.), diluted to $5 \mu \mathrm{g} / \mathrm{ml}$ in $0.1 \mathrm{M}$ phosphate buffer saline (PBS, pH 7.2), and incubated in a humid chamber at $37^{\circ} \mathrm{C}$ for $1 \mathrm{~h}$, followed by incubation in the refrigerator $\left(2-8{ }^{\circ} \mathrm{C}\right)$ overnight. Next, the wells were washed four times with PBS containing $0.05 \%$ Tween (Sigma Chemical Co.) (PBS-T) and incubated for $2 \mathrm{~h}$ at $37{ }^{\circ} \mathrm{C}$ with $200 \mu \mathrm{l}$ of $3 \%$ bovine serum albumin (BSA; Sigma Chemical Co.) solution in PBS-T. The wells were then washed four times with PBS-T, and $100 \mu \mathrm{l}$ of PCR product diluted 1:25 in PBS were placed in duplicate into the wells of the microplates and incubated in a humid chamber at $37^{\circ} \mathrm{C}$ for $30 \mathrm{~min}$. The wells were washed three times with PBS-T, $100 \mu \mathrm{l}$ of $0.1 \mathrm{M} \mathrm{NaOH}$ were added, and the plate incubated at room temperature for $10 \mathrm{~min}$. The plate was washed once with $0.1 \mathrm{M} \mathrm{NaOH}$ and three times with $0.1 \mathrm{M}$ Tris-HCl. Afterwards, 0.4 pmol fluorescein $5^{\prime}$-labeled probe (5'-TGGTTTCGGAGATACAACGA-3'; Integrated DNA Technologies Inc., Coralville, IO, US) diluted in $200 \mu \mathrm{l}$ of hybridization solution [70\% SSPE5X (0.75 M sodium chloride, $0.05 \mathrm{M}$ sodium phosphate, $0.005 \mathrm{M}$ EDTA), 30\% Formamide and 0.1\% SDS] was added to each well, followed by incubation in a humid chamber at $37{ }^{\circ} \mathrm{C}$ for $1 \mathrm{~h}$. The wells were washed three times with $6 \times \mathrm{SCC}$ solution $(0.9 \mathrm{M} \mathrm{NaCl}$ and $0.09 \mathrm{M}$ sodium citrate) and twice with $3 \times$ SCC solution $(0.45 \mathrm{M}$ $\mathrm{NaCl}$ and $0.045 \mathrm{M}$ sodium citrate $0.1 \%$ SDS). Next, $150 \mu \mathrm{l}$ of a solution containing 1\% BSA in PBS were added and the microplates incubated for $30 \mathrm{~min}$ at $37{ }^{\circ} \mathrm{C}$. Then, $150 \mu \mathrm{l}$ of anti-fluorescein antibodies IgG conjugated to peroxidase (Invitrogen-Thermo Scientific, Wilmington, DE, US) diluted 1:5000 in a solution containing 1\% BSA in PBS were added to each well of the microplate, which was incubated for $1 \mathrm{~h}$ in a humid chamber at $37{ }^{\circ} \mathrm{C}$. Subsequently, the microplate was washed four times with PBS-T, and $100 \mu \mathrm{l}$ of TMB (3,3',5,5'-tetramethylbenzidine; Sigma Chemical Co.) were added, followed by incubation at room temperature for $5 \mathrm{~min}$. The reaction was stopped by adding $50 \mu \mathrm{l}$ of $1 \mathrm{~N}$ sulfuric acid solution per well. The absorbance reading was performed in a microplate reader (Model 550, Bio-Rad Laboratories, Hercules, CA, US) at the wavelength of $450 \mathrm{~nm}$.

As an internal control, the human $\beta$-actin $(A C T B)$ gene was amplified and detected using protocol described by Gomes et al. [8], and a negative control (PCR mix without DNA) was included. The cut-off of the PCR-ELISA laboratorial platform to define the presence or absence of the human $A C T B$ gene was calculated using the mean absorbance reading of the negative PCR control (PCR mix without DNA) plus three standard deviations.

The lower limit of detection of PCR-ELISA laboratorial platform was defined by a positive control containing $3 \mathrm{ng}$ of genomic DNA of adult worms successively diluted 1:10 in water containing linear acrylamide (994:6 $\mathrm{v} / \mathrm{v}$ ) to obtain $300 \mathrm{pg}, 30 \mathrm{pg}, 3 \mathrm{pg}, 300 \mathrm{fg}, 30 \mathrm{fg}$, and $3 \mathrm{fg}$ of DNA. Considering that $S$. mansoni genome contain about $580 \mathrm{fg}$ [9], these concentrations correspond to 517.2, 51.7, 5.17, 0.52, 0.052, 0.0052 times its genome. These samples were submitted to PCR according to Gomes et al. [8]. Then, the PCR products were analyzed on a $6 \%$ polyacrylamide gel and the PCR-ELISA laboratorial platform.

Precision tests (repeatability and reproducibility) were carried out with six DNA samples extracted from human feces (three negatives and three positives for the presence of $S$. mansoni eggs), according to the KatoKatz technique. The repeatability test was performed by retesting four times the same samples in a single assay (intra-assay test). To measure the reproducibility, the same samples were tested in four separate trials in different days, by the same researcher (inter-assay test). The precision levels (repeatability and reproducibility) were measured by the variation coefficient (VC) of retesting the samples and using the equation: $\mathrm{VC}=$ Standard deviation/Mean $\times 100 \%$

\section{Phase II evaluation}

The assay was validated with 206 DNA samples previously extracted from stools that had been examined by Kato-Katz technique (12 slides) and PCR-ELISA platform 
commercial [7], employing the standardized conditions described above.

\section{Data analysis}

The correlation between the absorbance readings and the Log10[S. mansoni DNA] was measured with Pearson's coefficient and cut-off of the PCR-ELISA laboratorial platform was defined by a receiver operating characteristic curve (ROC Curve) analysis using GraphPad Prism 4.0 software (San Diego, CA, US). Taking the Kato-Katz technique (12 slides) as reference for schistosomiasis mansoni diagnosis, we compared the relative sensitivity and relative specificity rates obtained with the PCRELISA laboratorial and commercial platforms using a Chi square $\left(\mathrm{X}^{2}\right)$ test in the OpenEpi, v. 3.01 [10], and considering a level of significance of $p<0.05$. Agreement among the Kato-Katz technique and laboratorial and commercial PCR-ELISA platforms was defined by Kappa index, and interpreted according to Landis and Koch [11].

\section{Results}

Our analytical sensitivity result regarding the PCRELISA laboratorial platform was of $3 \mathrm{fg}$ of $S$. mansoni DNA, that equivalent to 0.0051 times the its genome [9]. Moreover, there was a positive correlation between the absorbance readings and the Log10[DNA S. mansoni], indicated by a Pearson's coefficient of $0.932,\left(\mathrm{r}^{2}=0.87\right.$, $p=0.002$ ) (Fig. 1). Unspecific amplification was not a concern because the primers used in the PCR to diagnose schistosomiasis mansoni are genus-specific [8] and do not cross-react with DNA from Ascaris lumbricoides,
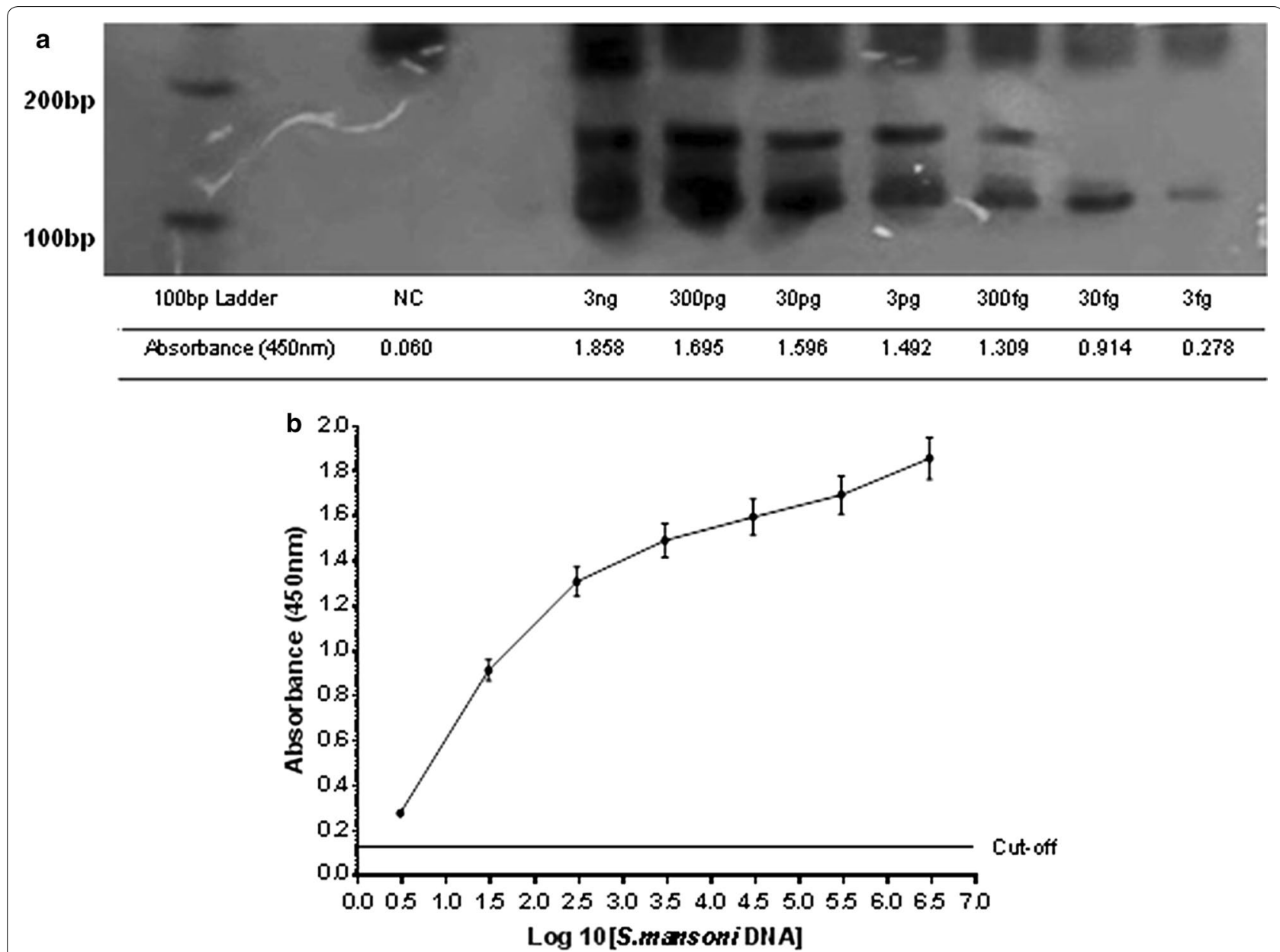

Fig. 1 a $6 \%$ polyacrylamide gel showing $110 \mathrm{pb}$ bands with decreasing intensity from $3 \mathrm{ng} / \mu \mathrm{l}$ to $3 \mathrm{fg} / \mu \mathrm{l}$. The corresponding absorbance readings presented by the PCR-ELISA laboratorial platform are described below each lane, decreasing from 1.858 to 0.278 , according to the concentration of S. mansoni DNA used in the PCR reaction. A 100 bp ladder marker (Promega, Madison, WI, USA) and a negative control (NC) are presented in the first two lanes. b Pearson's positive correlation between the Log10 [S. mansoni DNA] and absorbance readings ( $450 \mathrm{~nm})$. Pearson's coefficient $=0.932$ $\left(r^{2}=0.87, p=0.002\right)$ 
Ancylostoma duodenales, Taenia solium, and Trichiuris trichiuria [11].

The VCs obtained by the intra-assay test for the negative control samples were $3.12,1.94$, and $7.68 \%$, and the $\mathrm{VCs}$ for the positive control samples were 5.52, 2.72, and $0.82 \%$. The VCs obtained by the inter-assay test for the negative control samples were 19.26, 15.37, and 13.26\%, and for the positive control samples were $7.74,6.28$, and $5.86 \%$.

Kato-Katz technique detected 38 individuals (38/206) with $S$. mansoni eggs in their feces, resulting in a prevalence rate of $18.4 \%$ in the studied area. Considering 0.136 as the cut-off point (area under the curve $=0.97$ ), we established that the disease prevalence rate indicated by the PCR-ELISA laboratorial platform was $25.2 \%(52 / 206)$. This rate was higher than the $18.4 \%(38 / 206 ; p=0.01)$ rate obtained with the Kato-Katz technique and was not significantly different from that obtained with the PCRELISA commercial platform $(30.1 \% ; 62 / 206 ; p=0.13)$.

Only one sample (1/38) Kato-Katz positive presented negative result according to the laboratorial or commercial PCR-ELISA platforms, indicating a relative sensitivity of $97.4 \%$ (CI 95\% 84.6-99.9). The negative samples in the laboratorial and commercial PCR-ELISA platforms were collected from two individuals, one who presented only two S. mansoni eggs per gram of faeces (EPG) and another who showed eight EPG by the Kato-Katz technique, respectively.

The relative specificity rates were $91.1 \%$ (CI 95\% 85.494.7) and $85.1 \%$ (CI 95\%: 79-89.7\%) since 15 of the 168 samples diagnosed as negative by the Kato-Katz showed positive results by the laboratorial and commercial PCRELISA platforms. Ten samples presented positive results only by the PCR-ELISA commercial platform (Table 1). The agreement among Kato-Katz technique and PCRELISA laboratorial platform was considered good $(\mathrm{K}=0.78)$. On other hand, the agreement of the laboratorial and commercial PCR-ELISA platforms results was considered excellent $(K=0.85)$ (Additional file 1 : Table S1).

\section{Discussion}

In this study, we propose a PCR-ELISA laboratorial platform for diagnosis of schistosomiasis mansoni. The relative specificity rate and agreement of the PCRELISA laboratorial platform increased from 91.1 to $95.0 \%$ and $0.78-0.88$ (data not shown) when 15 additional samples from individuals with discordant results were re-examined by Kato-Katz technique. These findings demonstrate the importance of evaluating a larger number of samples and a greater number of slides to reduce the number of false-negative results, since the limitation of the parasitological technique in detecting low parasitic burden is well established $[4,5]$.

Other encouraging aspects are that the PCR-ELISA laboratorial platform proposed herein showed performance similar to the molecular assays previously described [4, 12] with the advantage that it can be scaled to a large number of samples, and the results read objectively. Indeed, the PCR-ELISA laboratorial platform allows the processing of 46 samples per plate in duplicate and the results are read with a spectrophotometer. This processing requires considerably less time than the other conventional molecular or parasitological techniques to evaluate the same number of samples.

Schistosoma spp. has at least 600,000 copies of the $121 \mathrm{pb}$ repetitive sequence in each cell, which constitutes $12 \%$ of the $S$. mansoni genome [13]. Therefore, in this work, all procedures were done by a trained researcher and physical barriers were utilized in all sample handling steps of the laboratorial and commercial PCR-ELISA platforms to minimize the risk of contamination. The possibility of PCR inhibition was discarded because all samples had absorbance readings ranging from 0.328 to 1.159 (mean $=0.810)$, which were higher than the cut-off point defined for detection of the $A C T B$ gene $(0.133)$. It is important to note that the present study report the internal validation results and still is necessary carry out multicenter studies in reference laboratories in order to externally validate the platform in these settings.

Table 1 Prevalence and relative sensitivity and specificity rates of the PCR-ELISA laboratorial and commercial platforms, taking Kato-Katz technique (12 slides) as reference for schistosomiasis mansoni diagnosis

\begin{tabular}{llll}
\hline Assays & Prevalence rate (CI 95\%) & Relative sensitivity (CI 95\%) & Relative specificity (CI 95\%) \\
\hline $\begin{array}{l}\text { PCR-ELISA laboratorial plat- } \\
\text { form (500 mg feces) }\end{array}$ & $52 / 206(25.2 \%)(19.5-31.8)$ & $37 / 38(97.4 \%)(86.5-99.5)$ & $153 / 168(91.1 \%)(85.8-94.5)$ \\
$\begin{array}{l}\text { PCR-ELISA commercial plat- } \\
\text { form (500 mg feces) }\end{array}$ & $62 / 206(30.1 \%)(23.9-36.9)$ & $37 / 38(97.4 \%)(86.5-99.5)$ & $143 / 168(85.1 \%)(79-89.7)$
\end{tabular}

Difference between prevalence rates of the PCR-ELISA laboratorial and commercial platforms, $p=0.13$

Difference between relative specificity rates of the PCR-ELISA laboratorial and commercial platforms, $p=0.03$ 


\section{Limitations}

Ideally, parallel experiments should have been done to precisely compare the performance of the PCR-ELISA laboratorial and commercial platforms. However, as aforementioned, the commercial platform is no longer available for purchase.

\section{Additional file}

Additional file 1: Table S1. Agreement among PCR-ELISA laboratorial platform, Kato-Katz technique and PCR-ELISA commercial platform.

\section{Abbreviations}

PCR: polymerase chain reaction; ELISA: enzyme-linked immunosorbent assay; DNA: deoxyribonucleic acid; WHO: World Health Organization.

\section{Authors' contributions}

EO, LIG, PMC and AR made substantial contributions to conception and design of study and developed the PCR-ELISA laboratorial platform protocol. EO and LIG been involved in drafting the manuscript or revising it critically for important intellectual content. CS and LMVS made substantial contribu tions to acquisition and analysis of data. Each author should have participated sufficiently in the work to take public responsibility for appropriate portions of the content. All authors read and approved the final manuscript.

\section{Author details}

${ }^{1}$ Clinical Research and Public Politics in Infectious and Parasitic Diseases, Instituto René Rachou, Oswaldo Cruz Foundation (IRR/FIOCRUZ), Av. Augusto de Lima, 1715, Belo Horizonte, MG 30190-002, Brazil. ${ }^{2}$ Biology of the Schistosoma mansoni and its Interaction with Host, Instituto René Rachou, Oswaldo Cruz Foundation (IRR/FIOCRUZ), Av. Augusto de Lima, 1715, Belo Horizonte, MG 30190-002, Brazil.

\section{Acknowledgements}

Not applicable.

\section{Competing interests}

The authors declare that they have no competing interests.

\section{Availability of data and materials}

The datasets used and analysed in the current study are available from the corresponding author on reasonable request.

\section{Consent for publication}

Not applicable.

\section{Ethics approval and consent to participate}

This study involved Swiss albino mice and individuals living in the community of Pedra Preta, a rural locality of Montes Claros municipality considered a low endemicity area for schistosomiasis mansoni in the North of the state of Minas Gerais, Brazil. The use of mice was consented and followed the guidelines for animal research of the Ethics Committee on the Use of Animals of the Oswaldo Cruz Foundation (CEUA-Fiocruz License 0118/09). The use of human samples was approved in accordance with the ethical standards of the Ethical Review Committee of the Instituto René Rachou/Fiocruz, Brazil (No. 784/2008) and with the Helsinki Declaration of 1975, as revised in 1983. All participants signed the informed consent before of the samples collection.

\section{Funding}

No funding was received for this work.

\section{Publisher's Note}

Springer Nature remains neutral with regard to jurisdictional claims in published maps and institutional affiliations.

Received: 9 November 2017 Accepted: 6 July 2018

Published online: 11 July 2018

\section{References}

1. Katz N. Inquerito Nacional de Prevalência da Esquistossomose mansoni e Geo-helmintoses. 2018. http://tabnet.datasus.gov.br/cgi/sinan/inpeg/ RelatoriolNPEG.pdf. Accessed 10 May 2018.

2. Katz N, Chaves A, Pellegrino J. A simple device for quantitative stool thick smear technique in schistosomiasis mansoni. Rev Inst Med Trop São Paulo. 1972; 14:397-400.

3. World Health Organization (WHO). The control of schistosomiasis. Second report of the WHO expert committee. Technical Report series 830. Geneva, 1993.

4. Carneiro TR, Peralta RHS, Pinheiro MCC, Oliveira SM, Peralta JM, Bezerra FSM. A conventional polymerase chain reaction-based method for the diagnosis of human schistosomiasis in stool samples from individuals in a low-endemicity area. Mem Inst Oswaldo Cruz. 2013;108(8):1037-44.

5. Lamberton PH, Kabatereine NB, Oguttu DW, Fenwick A, Webster JP. Sensitivity and specificity of multiple Kato-Katz thick smears and a circulating cathodic antigen test for Schistosoma mansoni diagnosis pre and postrepeated-praziquantel treatment. PLoS Negl Trop Dis. 2014. https://doi. org/10.1371/journal.pntd.0003139.

6. Pontes LA, Dias-Neto E, Rabello A. Detection by polymerase chain reaction of Schistosoma mansoni DNA in human serum and feces. Am J Trop Med Hyg. 2002;66(2):157-62.

7. Hamburger J, Turetski T, Kapeller I, Deresiewicz R. Highly repeated short DNA sequences in the genome of Schistosoma mansoni recognized by a species-specific probe. Mol Biochem Parasitol. 1991;44(1):73-80.

8. Gomes LI, Marques LHS, Enk MJ, Oliveira MC, Coelho PMZ, Rabello A. Development and evaluation of a sensitive PCR-ELISA system for detection of Schistosoma infection in feces. PLoS Negl Trop Dis. 2010. https:// doi.org/10.1371/journal.pntd.0000664.

9. Gomes AL, Melo FL, Werkhauser RP, Abath FG. Development of a real time polymerase chain reaction for quantitation of Schistosoma mansoni DNA. Mem Inst Oswaldo Cruz. 2006:101:133-6.

10. Dean AG, Sullivan KM, Soe MM. OpenEpi: Open Source Epidemiologic Statistics for Public Health, Version 3.01 [updated 2013 April 06]. http:// www.openepi.com. Accessed June and July 2017.

11. Landis JR, Koch GG. An application of hierarchical kappa-type statistics in the assessment of majority agreement among multiple observers. Biometrics. 1977:33:363-74.

12. Pontes LA, Oliveira MC, Katz N, Dias-Neto E, Rabello A. Comparison of a polymerase chain reaction and the Kato-Katz technique for diagnosing infection with Schistosoma mansoni. Am J Trop Med Hyg. 2003;68(6):652-6.

13. Eraky MA, Aly NS. Diagnostic and prognostic value of cell free circulating Schistosoma mansoni DNA: an experimental study. J Parasit Dis. 2016. https://doi.org/10.1007/s12639-014-0626-0. 